\title{
Высокотемпературный отжиг макропористого кремния в потоке инертного газа
}

\author{
(C) Е.В. Астрова, Н.Е. Преображенский, С.И. Павлов, В.Б. Воронков \\ Физико-технический институт им. А.Ф. Иофрфе Российской академии наук, \\ 194021 Санкт-Петербург, Россия \\ E-mail: east@mail.ioffe.ru
}

(Получена 8 февраля 2017 г. Принята к печати 16 февраля 2017 г.)

\begin{abstract}
Интерес к спеканию макропористого кремния обусловлен возможностью целенаправленно изменять его структуру. Проведение спекания макропористых структур в атмосфере аргона вместо водорода упрощает требования к оборудованию и технике безопасности. В настоящей работе исследовано спекание макропористого кремния, происходящее в результате отжига при $T=1000-1280^{\circ} \mathrm{C}$ в горизонтальной трубе, продуваемой газами высокой чистоты: $\mathrm{Ar}$ или $\mathrm{Ar}+3 \% \mathrm{H}_{2}$. Эксперименты проводились на слоях с глубокими цилиндрическими макропорами, изготовленными с помощью электрохимического травления образцов с затравочными ямками на поверхности (упорядоченные поры) и без таковых (случайные поры). Морфология пористой структуры и происходящие в ней изменения после отжига изучались с помощью электронного и оптического микроскопов. Показано, что в зависимости от диаметра пор и температуры обработки происходит сглаживание поверхности пор, закрытие пор и образование поверхностной корки, сфероидизация и распад цилиндрических пор на отдельные полые сферы, появление тонкой структуры и огранки. Показано, что минимальной поверхностной энергией обладают плоскости (111). Обнаружено, что при отжиге макропористого кремния в атмосфере инертного газа происходит интенсивное термическое травление, что проявляется в увеличении пористости или даже полном исчезновении пористого слоя на краю образца. Кроме того, при отжиге, особенно в области низких температур, наблюдается появление окисного налета в виде пленки, шариков или длинных нитей, образующих стекловату. Наблюдавшиеся особенности объясняются наличием в инертном газе следов окислителя, приводящего к образованию легко летучего $\mathrm{SiO}$ и продуктов реакции с его участием.
\end{abstract}

DOI: 10.21883/FTP.2017.09.44884.8543

\section{1. Введение}

При отжиге пористого кремния в неокислительной атмосфере происходит значительное изменение его морфологии. Происходящие преобразования подпадают под представления о спекании и могут быть использованы для изменения структуры пористых слоев [1]. Так, спекание мезопористого кремния, состоящего из двух слоев: с низкой и высокой пористостью, нашло важное практическое применение в технологии структур Silicon On Insulator (SOI) [2,3] и солнечных элементов $[4,5]$. В обоих случаях образующаяся при отжиге тонкая беспористая корка используется для эпитаксиального наращивания активной части прибора, а механически непрочный слой для отделения от подложки $[6,7]$.

Значительная трансформация структуры наблюдается и в макропористом кремнии. Спекание макропор сопровождается распадом цилиндрических пустот на изомерные сферы и также образованием беспористой корки [8]. Если макропоры организованы в регулярную решетку, то при спекании можно сформировать сплошную полость под слоем кремния и получить структуру Silicon On Nothing (SON) [9]. Следуя этому принципу, в работах $[10,11]$ были изготовлены равноотстоящие друг от друга цилиндрические макропоры, радиус которых периодически варьировался с глубиной. Их подвергали спеканию, в результате которого узкие участки полых цилиндров зарастали, а более широкие, наоборот, увеличивали свой радиус и сливались с соседями. Благодаря образовавшемуся слоеному пирогу, состоящему из чередующихся слоев кремний-пустота, пластина разделялась на монокристаллические пленки толщиной в несколько микрон. Такая технология также будет полезна для разделения пластин на более тонкие образцы без больших потерь материала, которые неизбежны в случае использования обычной процедуры резки и последующей механической обработки. Имеются и другие задачи, для решения которых представляет интерес материал с закрытыми порами, например для анодов литий-ионных аккумуляторов.

Следует сказать, что в большинстве работ по спеканию пористого кремния термообработка производилось в высоком вакууме [12] или в водороде при разном давлении: от десятков мм рт. ст. до атмосферного [3,7-9,13]. Тем не менее в некоторых публикациях сообщалось об успешном использовании другой защитной атмосферы: $\mathrm{Ar}[14,15,10]$ или $\mathrm{He}+\mathrm{H}_{2}[16]$.

Цель настоящей работы состоит в изучении процессов спекания кремниевых микроструктур разной морфологии, изготовленных с помощью анодирования монокристаллического кремния в жидких электролитах и выявлении особенностей отжига в печи с горизонтальной трубой, которая продувалась аргоном высокой чистоты или аргоном, содержащим дополнительно $3 \%$ водорода. 
Таблица 1. Параметры образцов и режим их получения

\begin{tabular}{|c|c|c|c|c|c|c|c|c|}
\hline \multirow{2}{*}{ Образец } & \multicolumn{2}{|c|}{ Исходный Si } & \multicolumn{2}{|c|}{ Затравки } & \multirow{2}{*}{$\begin{array}{c}j, \\
\mathrm{~mA} / \mathrm{cm}^{2}\end{array}$} & \multirow{2}{*}{$\begin{array}{c}\text { Состав } \\
\text { электролита }\end{array}$} & \multirow{2}{*}{$l$, мкм } & \multirow{2}{*}{ Отжиг } \\
\hline & тип & $\rho, \mathrm{OM} \cdot \mathrm{cm}$ & тип решетки & $a$, мкм & & & & \\
\hline КЭФ-03 & $n$ & 0.3 & $R$ & 0.54 & 12 & $\mathrm{HF}: \mathrm{H}_{2} \mathrm{O}_{2}=1: 10$ & 56 & $11-07$ \\
\hline$p$-Si-22 B & $p$ & 15 & $R$ & 2.36 & 8 & 4\% HF DMF & 75 & $15-09$ \\
\hline AT-16 & $n$ & 15 & $H$ & 8.00 & 6 & $4 \% \mathrm{HF} a q+h v$ & 177 & $20-09$ \\
\hline$p$-Si-1 & $p$ & 15 & $R$ & 2.36 & 8 & 4\% HF DMF & 39 & $20-09$ \\
\hline AT-5 & $n$ & 5 & $H$ & 4.00 & 6.5 & $4 \% \mathrm{HF} a q+h v$ & 220 & $26-09$ \\
\hline $\begin{array}{l}\text { мембрана } \\
\text { SQ4-22 }\end{array}$ & $p$ & 15 & $S$ & 4.00 & 4 & $4 \% \mathrm{HF}$ DMF & 62 & 26-09 \\
\hline$p-\mathrm{Si}-20$ & $p$ & 15 & $R$ & 1.95 & 15 & То же & 36 & $14-11$ \\
\hline
\end{tabular}

Примечание. $H$ - гексагональная решетка затравок, $S-$ квадратная, $R-$ без затравок (random).

\section{2. Методика эксперимента}

Образцы для отжига (табл. 1) изготавливались с помощью электрохимического травления кремниевых пластин с ориентацией (100) и удельным сопротивлением $\rho=0.3-15$ Ом · см. Регулярные цилиндрические макропоры образовывались на месте затравочных ямок, сформированных на поверхности с помощью фотолитографии и последующего анизотропного травления в щелочном растворе. Эти затравки были организованы в гексагональную $(H)$ или квадратную $(S)$ решетку с периодом $a=4$ или 8 мкм. В образцах с полированной поверхностью (без затравочных ямок) макропоры образовывались за счет процесса самоорганизации и имели случайное расположение $(R)$ с характерным средним периодом $a=0.5-2.4$ мкм. Анодирование большинства образцов $n$-типа проводимости проводилось в водном растворе HF при подсветке обратной стороны пластины [17], образцов $p$-типа без подсветки в растворе НF на основе диметилформамида (DMF) [18]. Плотность тока анодирования составляла $4-15 \mathrm{MA} / \mathrm{cm}^{2}$, глубина пор $l=35-220$ мкм. В некоторых образцах, например AT-5, после анодирования затравочные ямки и подложка удалялись с помощью полировки, в результате чего получали мембрану со сквозными порами.

Для проведения отжигов в диапазоне $1000-1280^{\circ} \mathrm{C}$ использовалась муфельная печь с горизонтальной кварцевой трубой диаметром $\sim 46$ мм и длиной 500 мм, продуваемой аргоном высокой чистоты (ТУ 6-21-12-94) или смесью аргона с водородом $\left(97 \% \mathrm{Ar}+3 \% \mathrm{H}_{2}\right)$. Сoдержание примесей в них составляло: $\mathrm{O}_{2}<2 \cdot 10^{-4 \%}$, $\mathrm{H}_{2} \mathrm{O}<3 \cdot 10^{-4} \%$, расход газа 100 л/ч. Перед термообработкой образцы освежались в водном растворе плавиковой кислоты $\left(48 \% \mathrm{HF}: \mathrm{H}_{2} \mathrm{O}=1: 1\right)$, промывались в деионизованной воде, просушивались на центрифуге и располагались на кварцевой лодочке. В ряде случаев кроме пористых образцов одновременно отжигались и полированные с одной стороны свидетели. Если специально не оговорено, то образцы располагались лежа, пористой стороной вниз. Труба продувалась инертным газом, затем в нее задвигалась лодочка с образцами в течение 30 с. Образцы выдерживались при постоянной температуре в течение заданного времени и после этого лодочка выдвигалась в холодную зону на край трубы также в течение 30 с. После термообработки образцы раскалывались вдоль направления $\langle 110\rangle$. Структура поверхности и сколов изучались с помощью оптического микроскопа Nikon LV150 и сканирующего электронного микроскопа JSM 7001F (JEOL).

\section{3. Результаты и обсуждение}

\section{1. Роль следов окислителя в инертном газе}

Первое, что обнаружилось при проведении отжигов, это появление на поверхности образцов и свидетелей радужной пленки (рис. 1,a) и местами белого налета (рис. $1, b, c, d)$. В некоторых случаях белый налет образовывал сгустки, напоминающие вату (рис. 1,e). При большем увеличении можно было видеть, что эта вата состоит из длинных нитей толщиной 100-160 нм (рис. $1, f)$. Эти явления чаще наблюдались после низкотемпературной термообработки или при медленном охлаждении и не зависели от наличия в газовой атмосфере добавки водорода. Обработка таких образцов в плавиковой кислоте приводила к полному исчезновению как радужных разводов и белых налетов, так и ваты, что свидетельствует о том, что это двуокись кремния.

Второе - это появление ямок травления на краю свидетеля или на торце образца в виде круглых углублений (рис. 1,e; 2,a,c) или перевернутых тетраэдров, которые сверху выглядят как квадраты (рис. 2, b). Часто в круглых ямках, как и в незакрывшихся порах на поверхности пористых образцов, застревали частицы оксида кремния (рис. $1, d)$ или вата (рис. $1, e$ ).

Третье - это утоньшение пористого слоя на краю образца, в результате чего образовывалась характерная каемка шириной в десятки микрон с повышенной пористостью и обнажившейся подложкой (рис. $3, b$ ). Интенсивность термического травления пористого слоя зависит от расположения образцов относительно газового потока. На рис. 3, $а$ показаны образцы, вырезанные из 


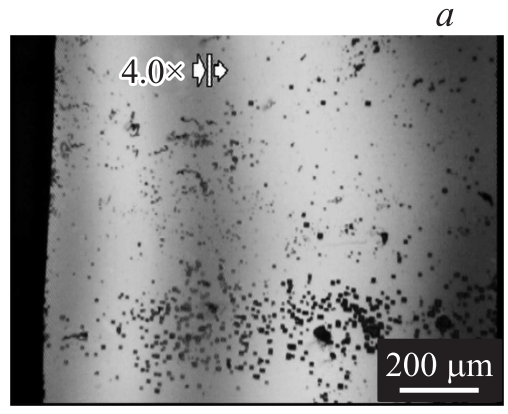

$d$

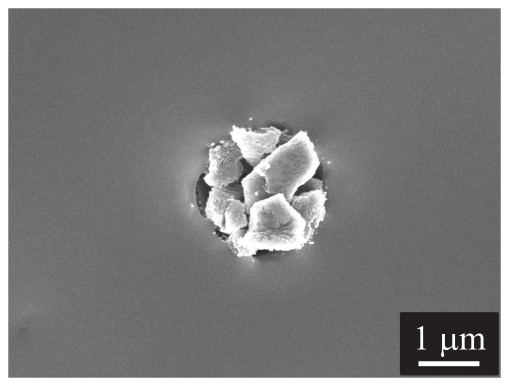

$b$

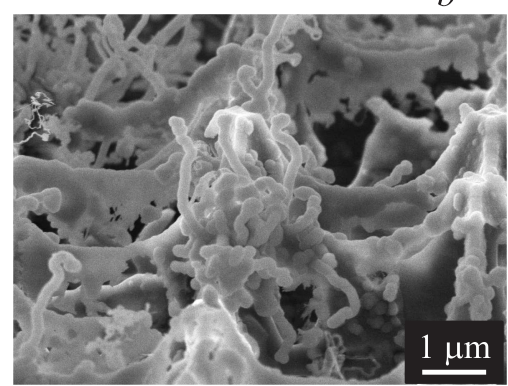

$e$

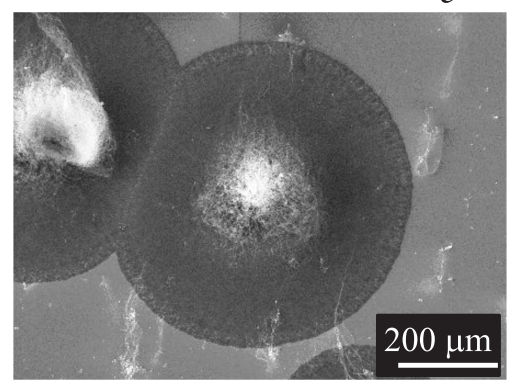

$c$

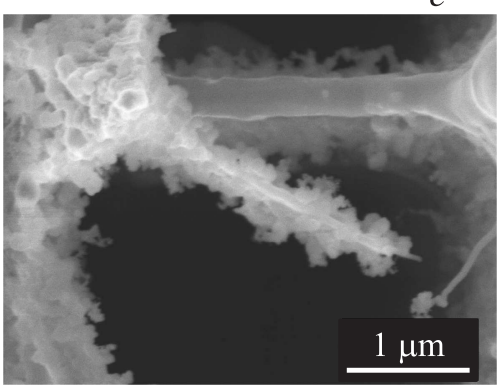

$f$

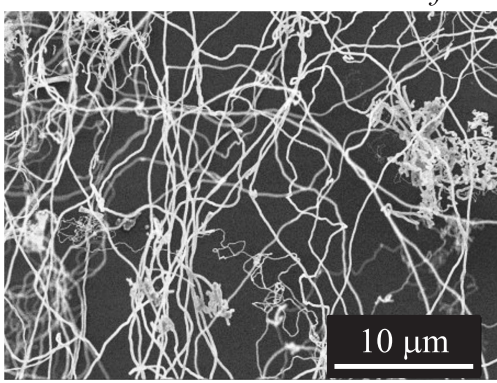

Рис. 1. Окисные образования на поверхности образцов после отжига: $a-$ ямки травления и прозрачная пленка переменной толщины на свидетеле $\left(T=1125^{\circ} \mathrm{C}\right) ; b$ и $c-$ белый налет на поверхности пористой структуры после отжига при $T=1050$ и $1000^{\circ} \mathrm{C}$ соответственно; $d-$ частицы оксида кремния в порах на поверхности мембраны АТ-5; $e-$ вата в круглой ямке травления на свидетеле $\left(T=1200^{\circ} \mathrm{C}\right)$ и $f$ - нити, образующие вату.

$a$

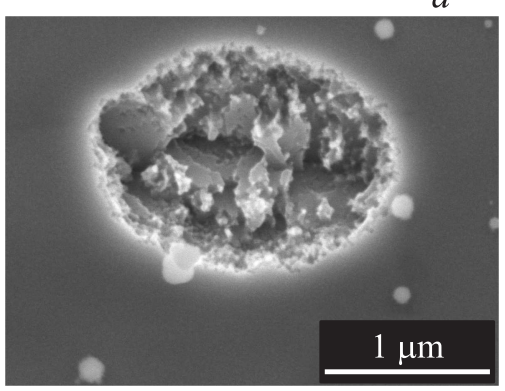

$b$

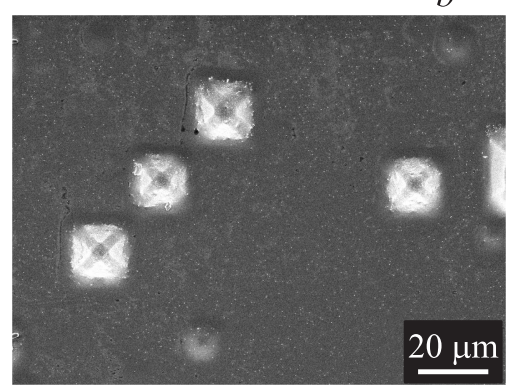

C

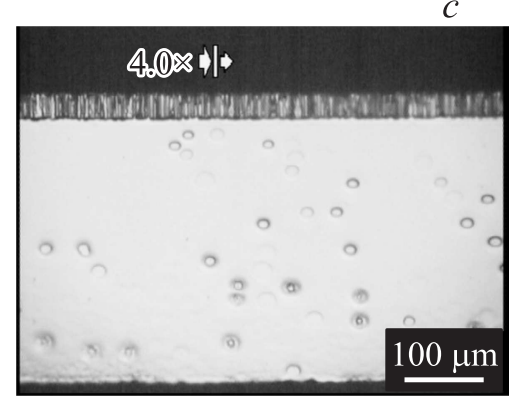

Рис. 2. Круглые и квадратные ямки травления на поверхности свидетелей $(a, b)$ и на торце образца $p$-Si-1 $(c)$, образовавшиеся в результате отжига при $T=1125-1130^{\circ} \mathrm{C}$ в течение $30-90$ мин.

пористой структуры $p$-Si-20 и при отжиге лежавшие в лодочке по-разному: 1 и 2 пористой стороной вверх, 3 и 4 пористой стороной вниз. Видно, что пористый слой на образцах 1 и 2 со стороны поступления газа полностью испарился, а чуть дальше стал черным, что говорит о возрастании пористости. В то же время кусочки 3 и 4, лежавшие лицом вниз, почти не подверглись травлению, которое наблюдалось только в некоторых местах на краю. Измерение массы образцов до и после отжига свидетельствует о том же: масса образцов 1 и 2 уменьшилась на $9.11 \mathrm{мг} / \mathrm{cm}^{2}$, образцов 3 и 4 на $1.54 \mathrm{Mг} / \mathrm{cm}^{2}$, т.е. потеря массы в последнем случае была в $\sim 6$ раз меньше. Слой с высокой пористостью выглядит черным из-за снижения коэффициента отражения. Поры в таком „черном кремнии“ увеличиваются в размерах и сливают- ся между собой, приобретая характерный вид червяков (рис. 3, c).

Известно, что при термообработке кремниевых пластин в среде, содержащей малое количество окислителя, происходят следующие реакции $[14,15,19]$ : образование твердофазной пленки двуокиси кремния, которая пассивирует поверхность,

$$
\mathrm{Si}(s)+\mathrm{O}_{2}(g) \rightarrow \mathrm{SiO}_{2}(s),
$$

и летучей моноокиси кремния, которая обусловливает травление поверхности,

$$
2 \mathrm{Si}(s)+\mathrm{O}_{2}(g) \rightarrow 2 \mathrm{SiO}(g) .
$$

Соотношение между скоростями этих реакций зависит от температуры и парциального давления кислорода [20]. 
$a$
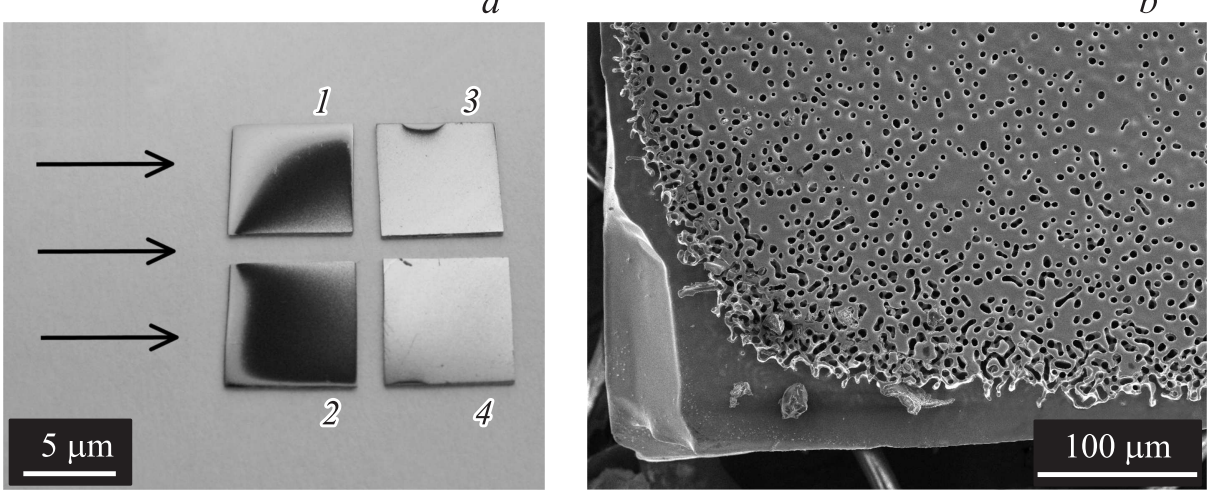

$c$
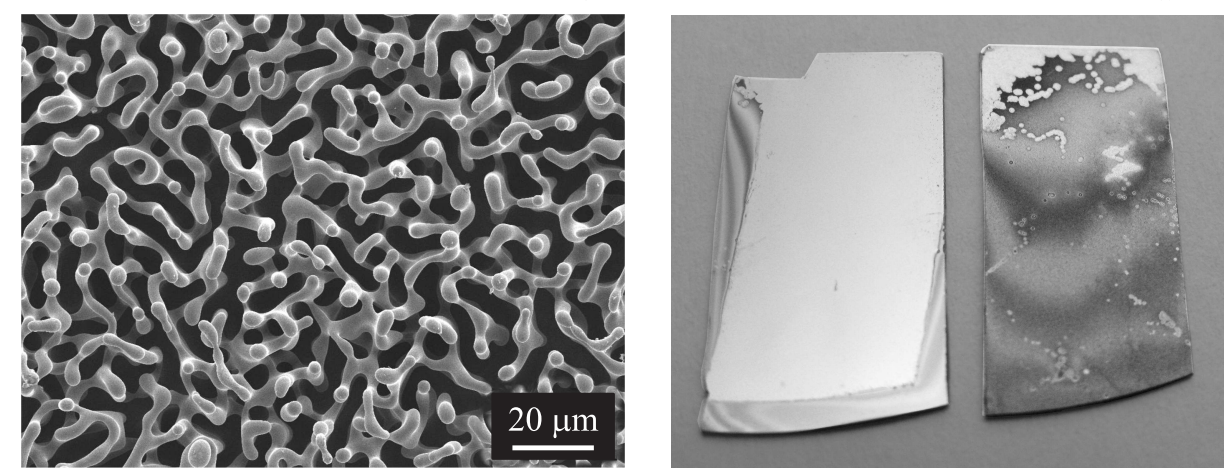

Рис. 3. Неравномерное термическое травление пористого слоя и осаждение $\mathrm{SiO}_{2}: a-$ „испарение“ пористого слоя в зависимости от расположения в лодочке, $b-$ край образца $p$-Si-7 с обнажившейся подложкой, $c$ - SEM-изображение „черного кремния“. Режим отжигов см. в табл. 2: $a, c-$ отжиг $14-11, b-$ отжиг при $T=1225^{\circ} \mathrm{C}$ в течение 160 мин $\left(\mathrm{Ar}+\mathrm{H}_{2}\right) . d-$ образование окисной пленки на неприкрытой поверхности кремния. Правый свидетель располагался поверх левого (отжиг $1200^{\circ} \mathrm{C}, 2$ ч, $\left.\mathrm{Ar}\right)$.

При фиксированной концентрации $\mathrm{O}_{2}$ реакция (1) преобладает при низких температурах, в результате чего на поверхности вырастает слой $\mathrm{SiO}_{2}$. При более высоких температурах преобладает реакция (2), и это приводит к очищению поверхности кремния. Кроме того, образовавшиеся продукты реакции также участвуют в последующем взаимодействии: моноокись с кислородом приводит к реокислению и осаждению твердого оксида:

$$
2 \mathrm{SiO}(g)+\mathrm{O}_{2}(g) \rightarrow 2 \mathrm{SiO}_{2}(s),
$$

а реакция кремния с двуокисью к разложению с образованием газообразного $\mathrm{SiO}$ :

$$
\mathrm{Si}(s)+\mathrm{SiO}_{2}(s) \rightarrow 2 \mathrm{SiO}(g) .
$$

Как было показано в работе [19], где были проведены опыты на кремниевых пластинах, при малых парциаль-

Таблица 2. Режимы отжига

\begin{tabular}{c|c|c|c|c}
\hline Отжиг & Образцы & $T,{ }^{\circ} \mathrm{C}$ & $t$, мин & Атмосфера \\
\hline $11-07$ & КЭФ-03 & 1130 & 90 & $\mathrm{Ar}+\mathrm{H}_{2}$ \\
$15-09$ & $p$-Si-22 B & 1200 & 120 & $\mathrm{Ar}$ \\
$20-09$ & $\mathrm{AT}-16, p-\mathrm{Si}-1$ & 1200 & 120 & $\mathrm{Ar}+\mathrm{H}_{2}$ \\
$26-09$ & $\mathrm{AT}-5, \mathrm{SQ} 4-22$ & 1280 & 120 & $\mathrm{Ar}+\mathrm{H}_{2}$ \\
$14-11$ & $p$-Si-20 & 1225 & 390 & $\mathrm{Ar}+\mathrm{H}_{2}$
\end{tabular}

ных давлениях кислорода $\left(<3 \cdot 10^{-5}\right.$ атм) реакции (2) и (4) отвечают за появление шероховатости и ямок травления, а реакция (3) может быть причиной реосаждения $\mathrm{SiO}_{2}$ в виде неравномерно распределеных по толщине пленок или узких и длинных нитей. Существенную роль в реакциях (1)-(4) играет слой на границе кремния с газовой фазой, в котором скорость потока равна нулю. Реагенты и продукты реакции в нем перемещаются только за счет диффузии. Поэтому в узких зазорах между пластинами кремния образование ямок травления и окисных покрытий подавлено, что объясняется насыщением зазора парами $\mathrm{SiO}$, который предотвращает дальнейшее испарение с поверхности. Действительно, в наших экспериментах вата и ямки травления появлялись обычно на краях образца или в небольших углублениях на поверхности (см. рис. 1 и 2), а скорость термического травления пористого слоя сильно зависела от распределения газового потока в трубе. Появление окисных образований - это результат реосаждения из газовой фазы. Как видно из рис. $3, d$, если свидетель прикрыть другим свидетелем, то окисная пленка, придающая радужную окраску, появляется только на неприкрытых частях образца. Наблюдающийся нами процесс термического травления пористого кремния при отжиге в инертной атмосфере сильнее выражен, чем монолитного кремния, благодаря его развитой по- 


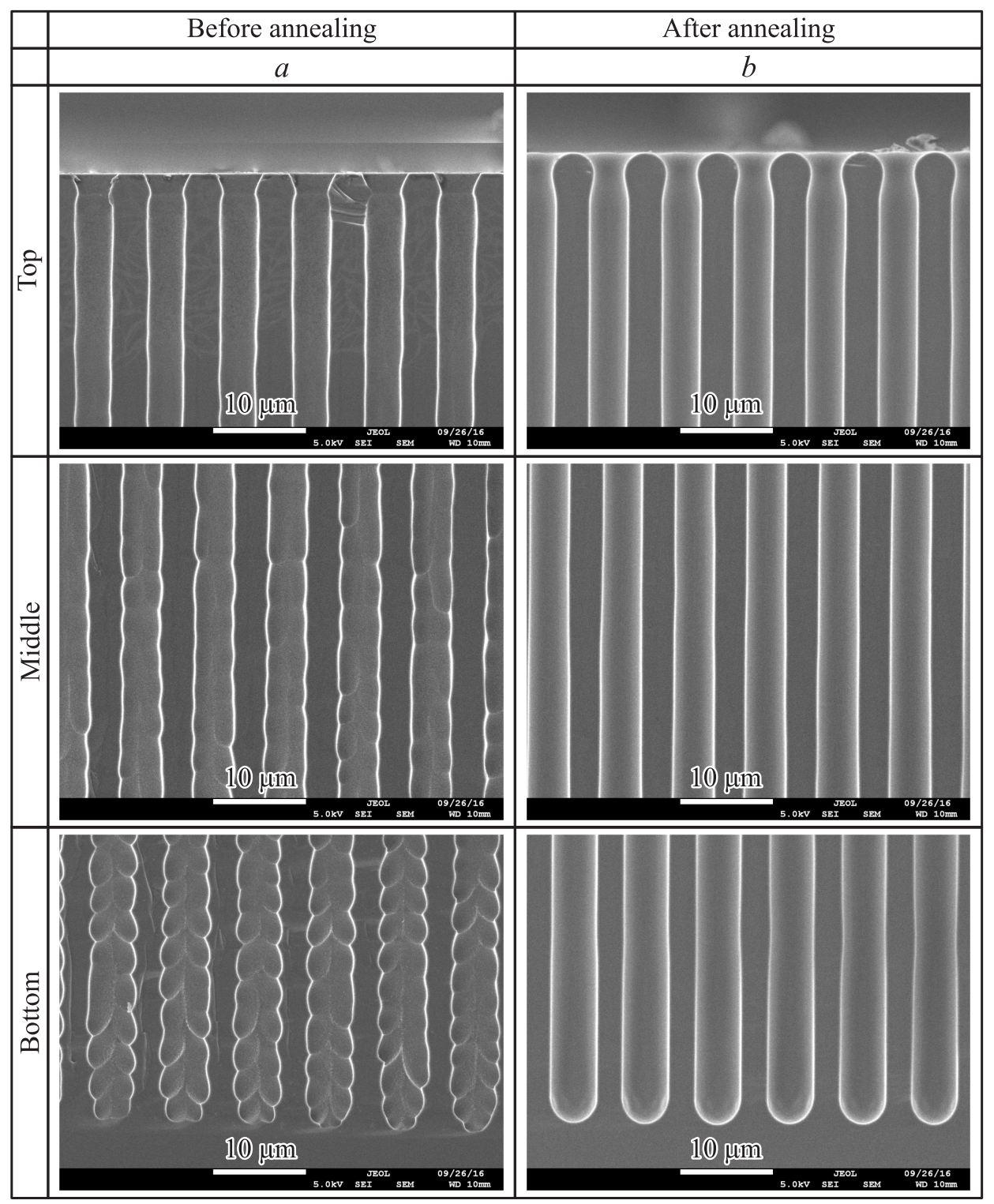

Рис. 4. Поперечное сечение макропор в образце АТ-16 до $(a)$ и после $(b)$ отжига 20-09. Показана морфология пор на разной глубине от поверхности. Масштабный отрезок 10 мкм.

верхности. Следует отметить, что давление насыщенных паров $\mathrm{Si}$ при температуре проводившихся отжигов на 2 порядка ниже, чем $\mathrm{SiO}$ [21], т. е. процессы термического травления связаны не с испарением самого кремния, а с испарением его моноокиси.

\section{2. Изменение морфологии пор}

Изменение морфологии зависело от исходной пористой структуры, температуры и длительности термообработки. На рис. 4 показаны изменения, произошедшие в образце АТ-16 с глубокими цилиндрическими макропорами диаметром $d=3.8$ мкм, нижняя часть которых имеет тенденцию к ветвлению. Здесь имеются участки с большей кривизной поверхности, радиус которых составляет 700 нм. На сколе образца после отжига видно, что искривленные участки исчезли и внутренняя поверхность макропор стала гладкой по всей глубине. На изображениях верхней (рис. 5,a) и нижней (рис. $5, b$ ) частей макропор можно видеть появление тонкой структуры в виде фигуры со встречно расположенными „рыбьими хвостами“ (рис. 5,c) и шестиугольника (рис. 5,d). На рис. 6 и 7 показана поверхность образца в области, подвергшейся анодированию, т.е. с затравками и макропорами, и в области, где изначально имелись только затравочные ямки глубиной 3.3 мкм. В обеих областях затравочные ямки исчезли, оставив на поверхности либо круглые отверстия цилиндрических пор (рис. 6, $c$ и $d$ ), либо сглаженную поверхность с высотой рельефа $\sim 0.4$ мкм. (рис. 7, $c$ и $d$ ). 


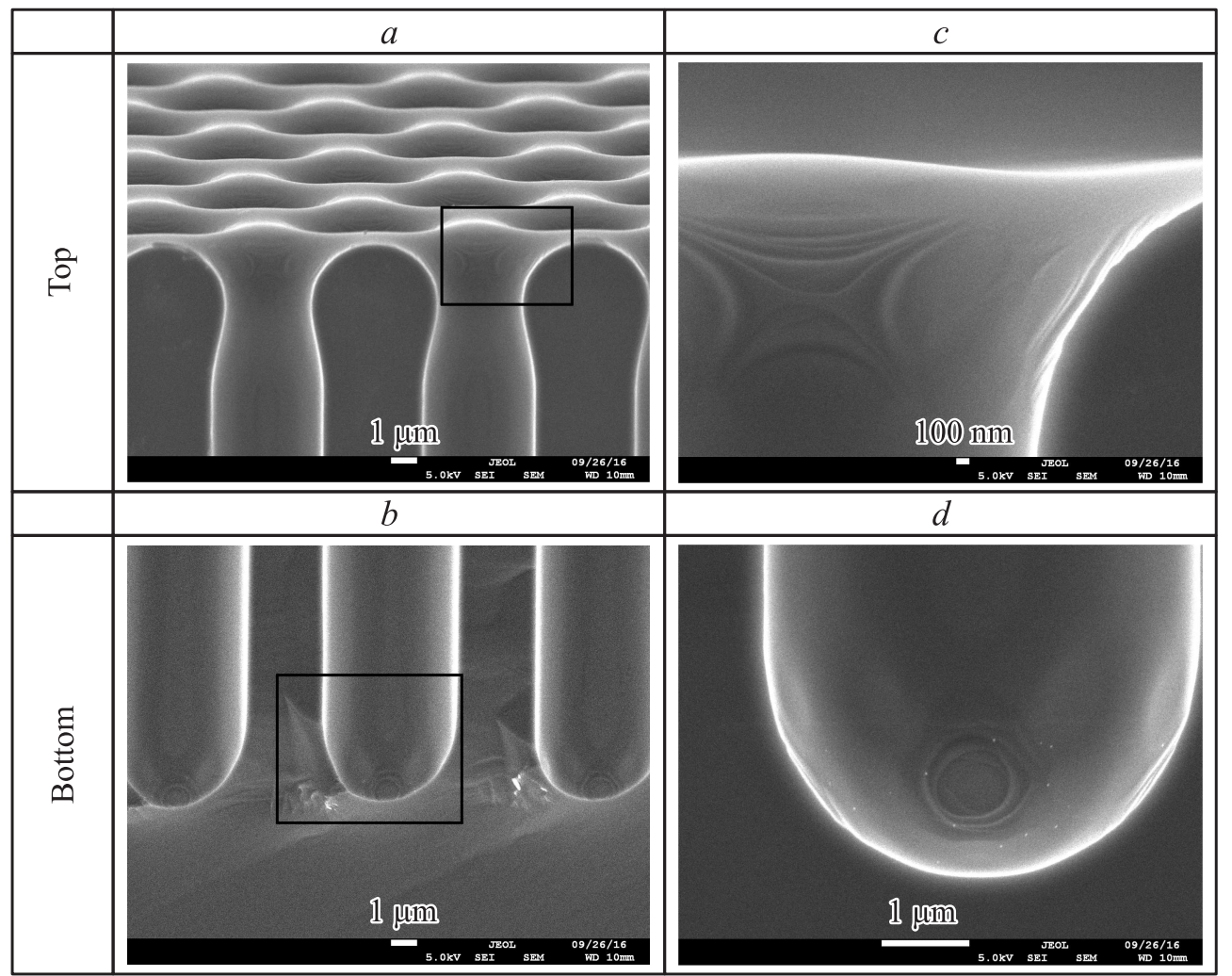

Рис. 5. Верхняя ( $a$ и $c)$ и нижняя $(b$ и $d)$ часть пористой структуры образца АТ-16 после отжига при разном увеличении. Сечение плоскостью (110). Масштабные отрезки: $a, b, d-1$ мкм, $c-100$ нм.

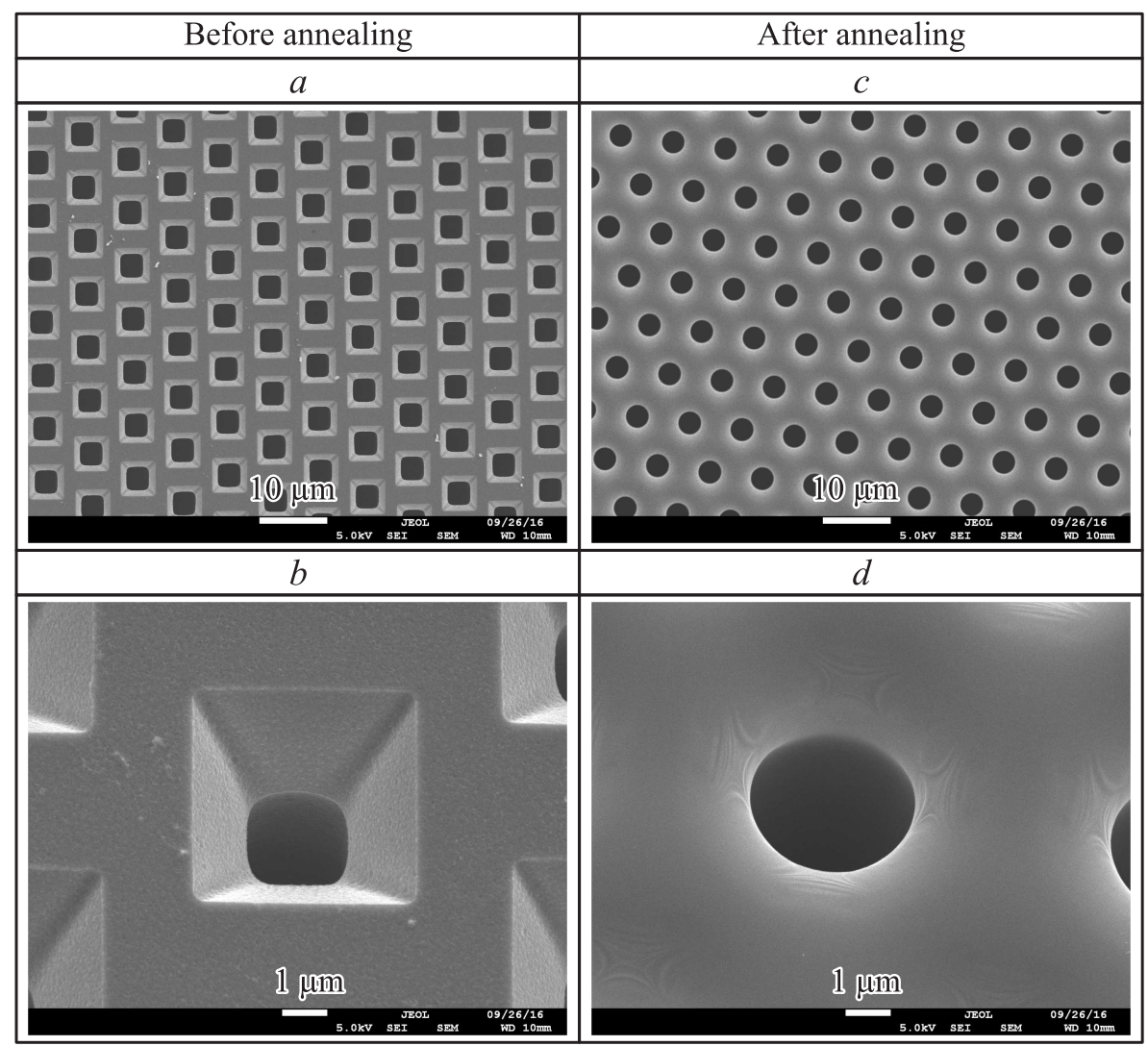

Рис. 6. Поверхность образца АТ-16 в области с макропорами до $(a$ и $b)$ и после $(c$ и $d)$ термообработки. $b$ и $d-$ наклонные изображения. Масштабные отрезки: $a, c-10$ мкм, $b, d-1$ мкм. 


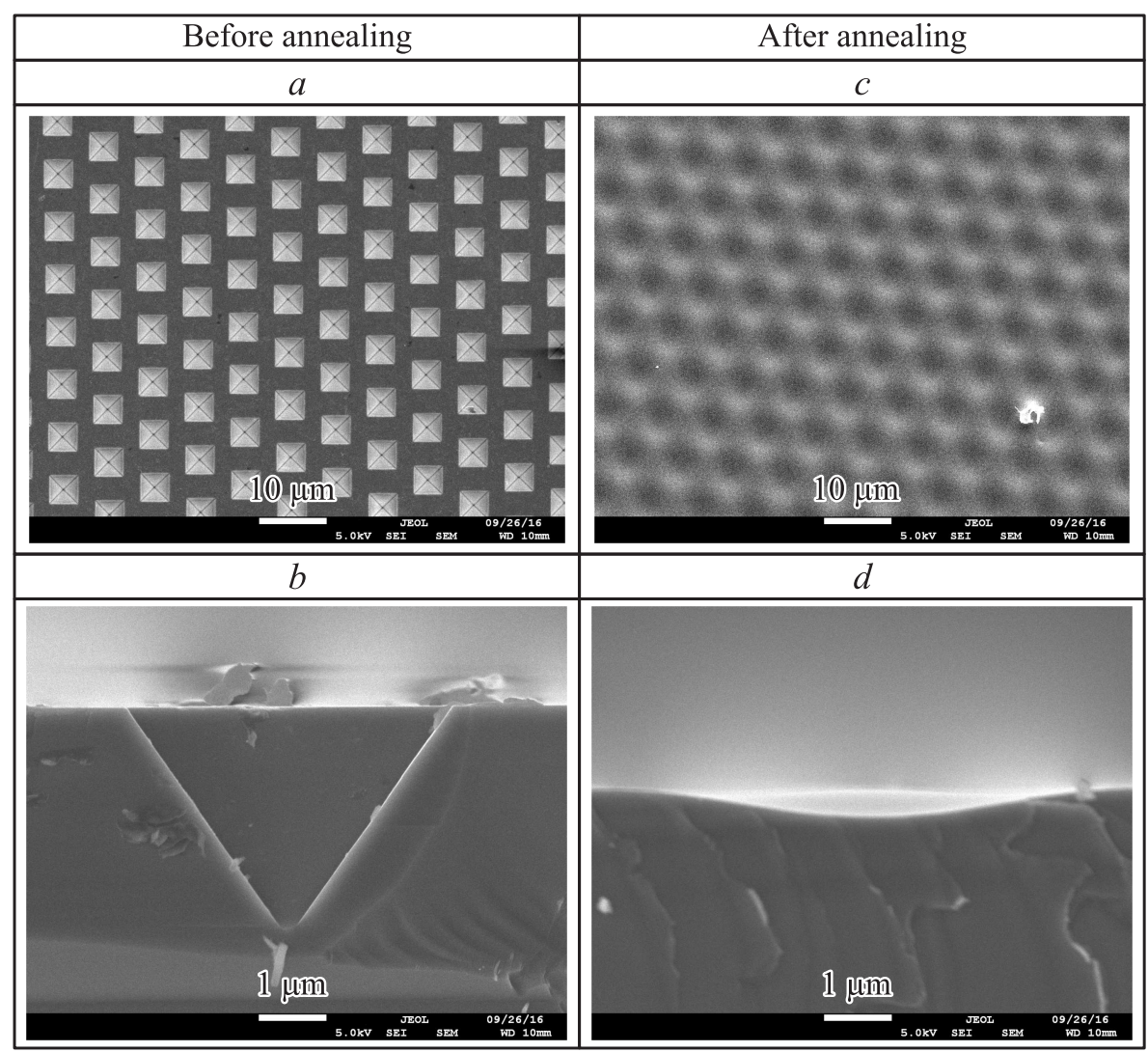

Рис. 7. Поверхность и поперечное сечение образца АТ-16 в области затравок до $(a$ и $b)$ и после $(c$ и $d)$ термообработки. Масштабные отрезки: $a, c-10$ мкм, $b, d-1$ мкм.
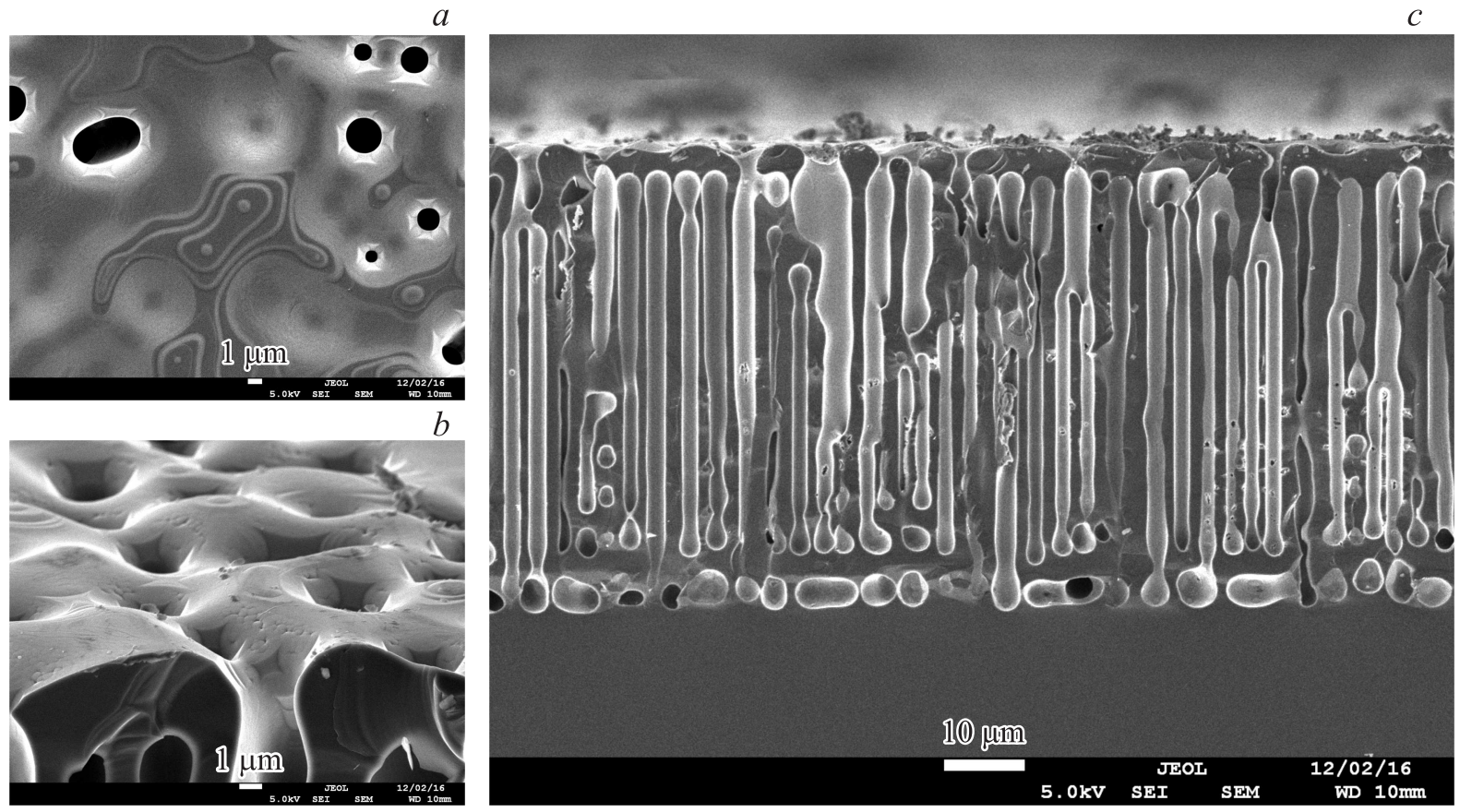

Рис. 8. Фрагмент поверхности ( $a$ и $b)$ и поперечное сечение $(c)$ образца $p$-Si-22 В после отжига. Масштабный отрезок: $a$ и $b-1$ мкм, $c-10$ мкм. 

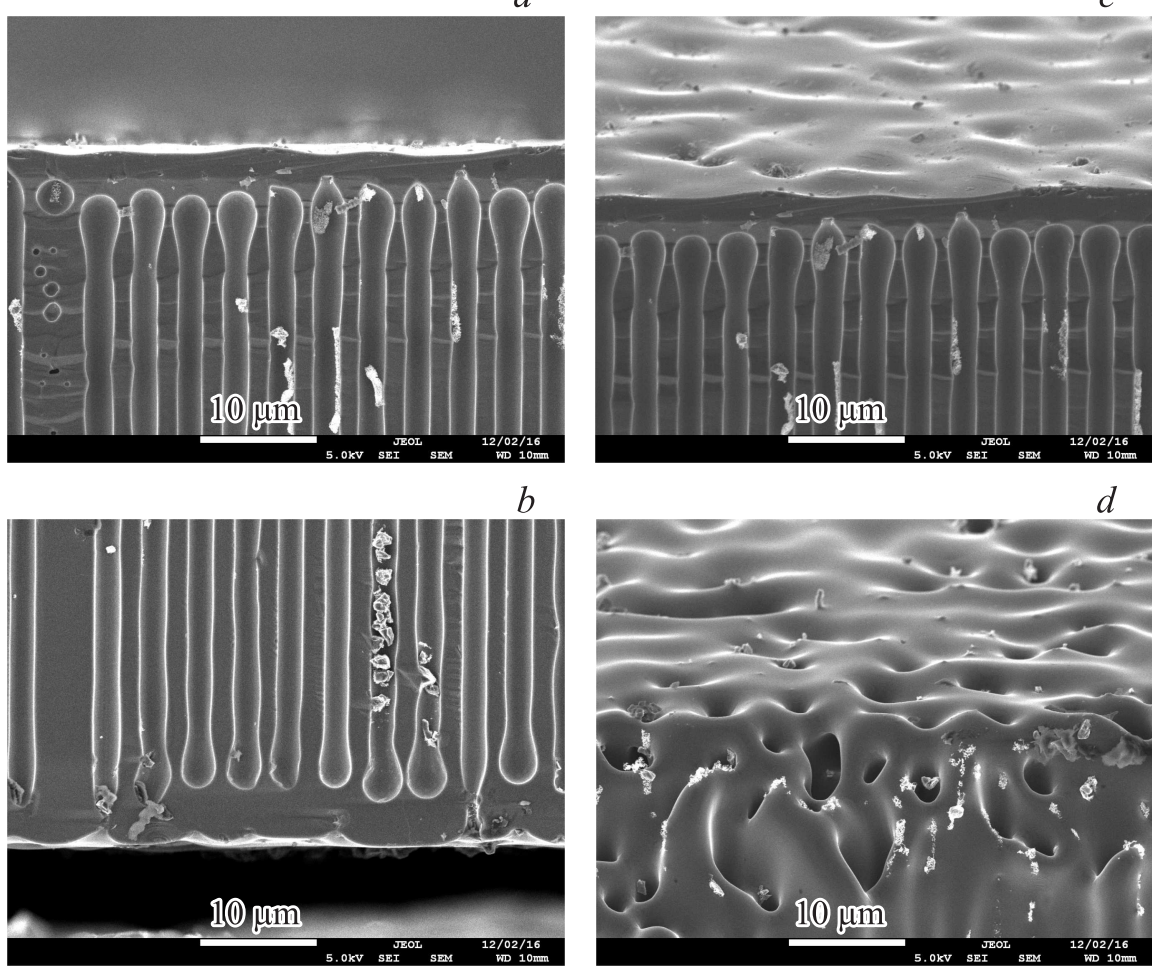

Рис. 9. Образование корки, сглаживание поверхности и торца у мембраны AT-5, поперечное сечение верхней части (a), нижней части $(b)$ и наклонное изображение $(c$ и $d): a, b, c$ - скол, сделанный после отжига, $d$ - отожженный торец. Масштабный отрезок 10 мкм.

$a$

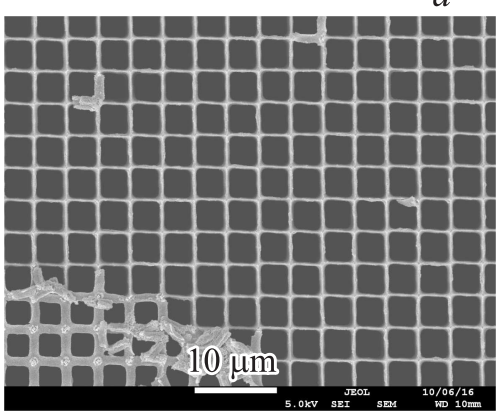

$b$

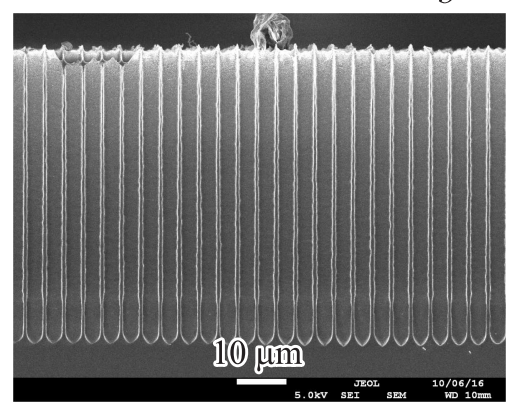

C

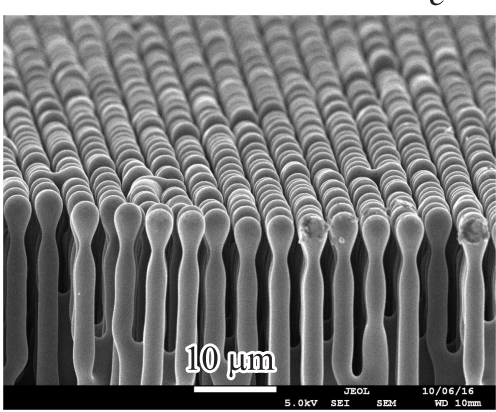

Pис. 10. SEM-изображение образца SQ4-22 до $(a, b)$ и после $(c)$ отжига при $1280^{\circ} \mathrm{C}$. Масштабный отрезок: $a, b, c-10$ мкм.

Более радикальная трансформация морфологии при той же температуре $1200^{\circ} \mathrm{C}$ произошла в неупорядоченных структурах с меньшим диаметром пор (среднее значение 1.6 мкм). На поверхности образцов, где произошло образование корки, видна тонкая структура в виде точек, окруженных концентрическими линиями (рис. 8,a) и четырех „рыбьих хвостов“ вокруг каждой из незаросших пор (рис. $8, a, b$ ). На поперечном сечении (рис. 8,c) можно видеть, как происходит сфероидизация пор, которая начинается на конце цилиндрических пор на границе с подложкой, затем образуются перемычки, по которым отделяются круглые поры. Последние коегде коагулируют с соседями.
Одновременно с образцом АТ-16 отжигалась часть образца АТ-5, имеющего диаметр пор 2.2 мкм. В нем не наблюдалось сколь-либо заметных превращений, кроме залечивания мелких поверхностных царапин, образовавшихся при полировке. Только повышение температуры отжига до $1280^{\circ} \mathrm{C}$ обеспечило спекание. На рис. 9 показана мембрана АТ-5 после термообработки. Здесь наблюдается выраженная реорганизация структуры: зарастание пор как на верхней, так и на нижней поверхности с образованием беспористого слоя (корки) толщиной 2-4 мкм (рис. 9, $a$ и $b$ ). Зарастание пор на поверхности и сглаживание рельефа на торце образца хорошо видны на рис. 9, $c$ и $d$. 
Отжиг сетчатой структуры SQ4-22 при $1280^{\circ} \mathrm{C}$ приводит к образованию в узлах решетки столбиков с утолщением в верхней части. Структура напоминает вертикально стоящие спички головками вверх (рис. $10 \mathrm{c}$ ). Действительно, стремление к минимальной поверхности предписывает столбику эволюцию, при которой в изотропном случае она должна завершаться шарообразным наростом и, в конце концов, разделиться на отдельные сферы [22].

На рис. 11, $а$ показан вид сверху такой сферической головки. Здесь на выпуклой поверхности можно видеть 4 шестиугольника, подобных тем, что наблюдались после отжига на вогнутой поверхности в нижней части макропор (рис. 5,d). Центры этих шестиугольников располагаются на расстоянии $f=0.8 D$ друг от друга, где $D$ - диаметр сферы. Если рассматривать эти точки как стереографические проекции кристаллографических направлений, то можно видеть, что они близки к значению, которое получается для направлений $\langle 111\rangle$ $\left(f=D \cdot \cos \left(35^{\circ}\right)=0.82 D\right)$. На поперечном сечении, которому соответствует плоскость (110) (рис. 11, $b$ ), эти шестиугольники располагаются под углом $35^{\circ}$ относительно направления $\langle 110\rangle$, что также согласуется с тем, что это грани (111). Помимо этих фигур, на рис. 11, a можно видеть также менее выраженную огранку четырьмя плоскостями, следы которых перпендикулярны плоскости изображения. Проекции этих граней располагаются на окружности на концах диаметров, расположенных под углом $45^{\circ}$ к горизонтали. Исходя из ориентации исходной сетчатой структуры относительно кристаллографических осей образца можно заключить, что это плоскости (100). Другие грани, проекции которых также находятся на окружности, образуют более короткие прямые линии вдоль вертикального и горизонтального направлений. Им соответствуют кристаллографические плоскости (110). Поскольку размер граней (111) превосходит все остальные, можно заключить, что (111) является плоскостью с наименьшей поверхностной энергией, за ней следуют плоскости (100) и затем (110). Эти результаты согласуются с данными, полученными при исследовании равновесной формы кремния в работе [23], и с данными работ [7,24].

Преобразование структуры макропористого кремния происходит в результате спекания, т.е. диффузионной деформации, происходящей под действием сил поверхностного натяжения [25]. Движущей силой процесса спекания является минимизация поверхностной энергии. Изменение формы и размера пустот происходит за счет массопереноса под действием капиллярных (лапласовских) сил, возникающих на участках пористой структуры с кривизной, отличной от нуля. Согласно классической теории, лапласовское давление $p_{c}$, которое приложено к поверхности одиночной поры, пропорционально поверхностному натяжению $\alpha$ и обратно пропорционально радиусу кривизны $R$. В случае цилиндрических пор $p_{c}=-\alpha / R$. Оценки показывают, что для цилиндрической поры в кремнии диаметром 1.2 мкм
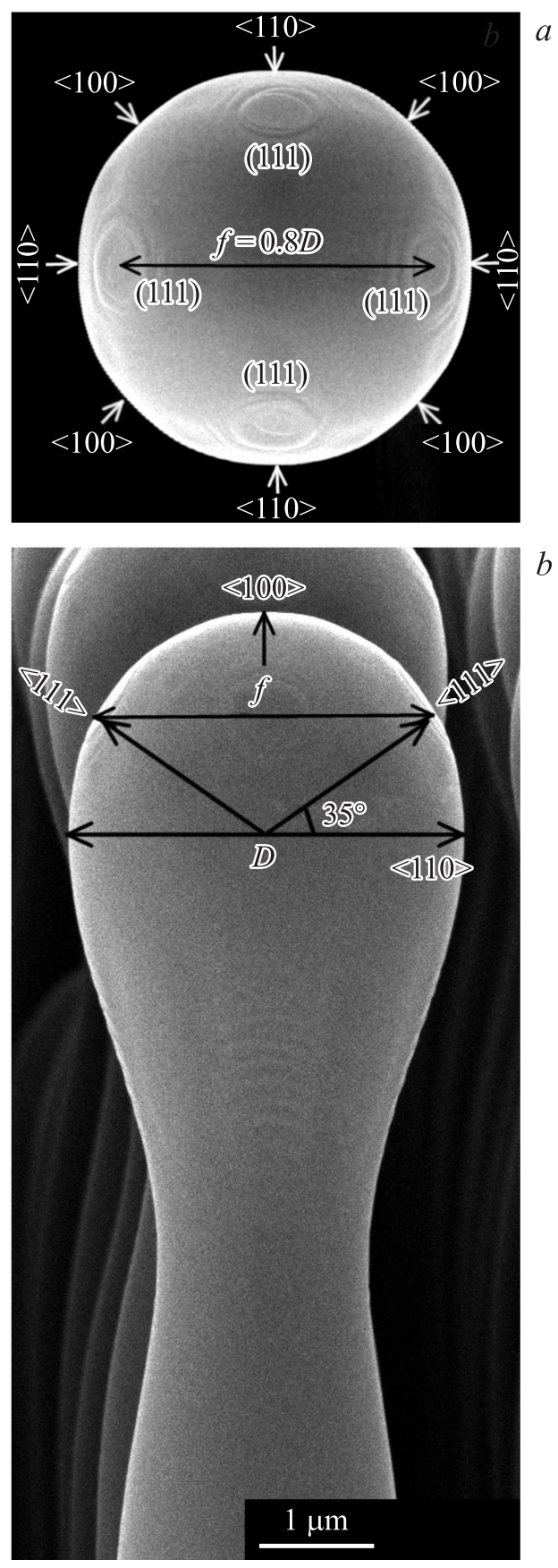

Рис. 11. Огранка сферической головки в отожженном образце SQ4-22: $a-$ вид сверху, $b-$ поперечное сечение плоскостью (110).

при $\alpha=6.24 \cdot 10^{14}$ эВ/см ${ }^{2}$ [13] это давление составляет около 17 атмосфер. Цилиндрическая полость является неравновесной и стремится изменить свою форму, превратившись в сферу, или при высоком аспектном отношении глубины поры к ее диаметру разделиться на несколько изомерных сфер [22,26], что и наблюдалось в работах $[8,9]$. Перемещение атомов по поверхности изменяет форму поры, сохраняя неизменным ее объем. При заращивании поры происходит транспорт атомов 

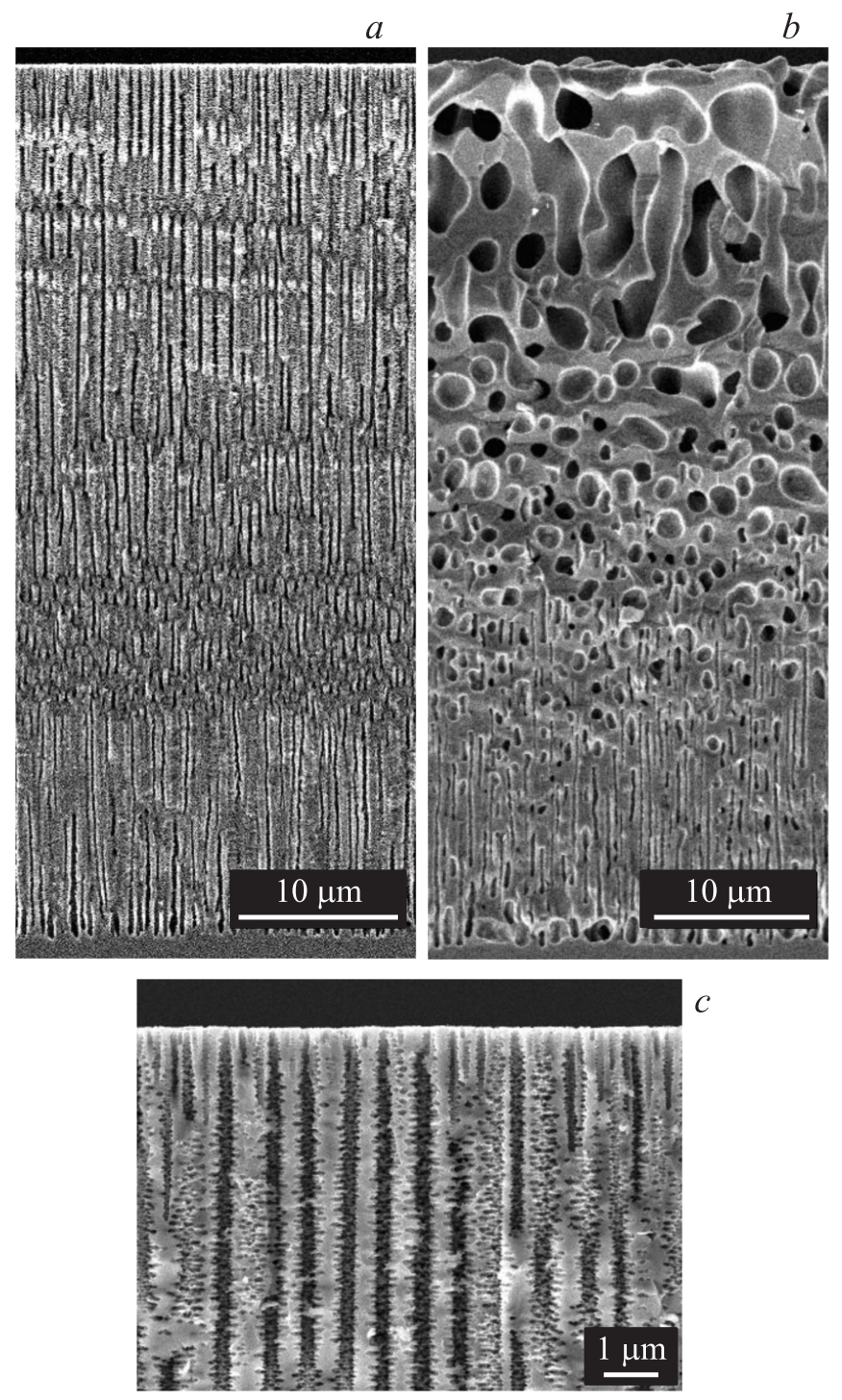

Рис. 12. Спекание пористого кремния в образце КЭФ-03: $a-$ поперечное сечение исходной структуры, $b-$ после отжига, $c$ - верхняя часть структуры до отжига при большем увеличении.

из объема к поверхности поры, что сопровождается уменьшением ее объема. Механизмом массопереноса при спекании пористого кремния является объемная либо поверхностная диффузия атомов $\mathrm{Si}$. Как известно, самодиффузия в $\mathrm{Si}$ осуществляется по вакансионному механизму [27]. Согласно модели Гегузина [25], вокруг вогнутой поверхности поры в кристаллическом веществе концентрация вакансий повышена. Чем выше кривизна, тем больше концентрация вакансий относительно равновесного значения. Диффузия вакансий от поры означает движение атомов во встречном направлении, т. е. к заращиванию поры.

В макропористом кремнии мы имеем дело не с изолированной порой, а с ансамблем пор. Этому ансамблю соответствует средний уровень пересыщения вакансиями. Концентрация вакансий вокруг пор большого диаметра меньше, чем средняя в пористом слое. К ним направлен поток вакансий, в результате чего размер пор растет. В случае малых пор наоборот. Таким образом, увеличение размера больших пор происходит за счет поглощения маленьких (процесс коалесценции). Самая крупная из пор - это поверхность, ее радиус равен бесконечности и она служит стоком, которому поры отдают свои вакансии. Поэтому на поверхности образуется беспористая корка. Коллективное поведение ансамбля пор демонстрирует образец КЭФ-03 с переменной пористостью (рис. 12). В исходной пористой структуре между основными вертикальными каналами диаметром 220 нм имеются горизонтальные, так называемые, пробойные поры диаметром 60 нм (рис. 12,c). В результате отжига пробойные поры малого диаметра полностью зарастают, а более крупные каналы распадаются на сферы (рис. 12,b). На границе с подложкой, как и в остальных образцах, наблюдается сфероидизация и укрупнение пор. В исходной структуре пористость убывает по мере продвижения вглубь. Как известно, в материале с более высокой пористостью эффективный коэффициент диффузии выше [25], поэтому в результате отжига в верхней области под коркой образуются наиболее крупные полости (2.5-4.3 мкм), размер которых постепенно убывает с глубиной.

\section{4. Заключение}

При отжиге макропористого кремния в потоке инертного газа происходят процессы массопереноса, термического травления и реосаждения твердой двуокиси кремния. Изменение морфологии и огранка протекают за счет транспорта атомов кремния в соответствии с законами спекания пористых материалов. Как на вогнутых, так и на выпуклых поверхностях структуры после отжига наблюдается огранка плоскостями (111), (100) и (110), среди которых наименьшая поверхностная энергия соответствует плоскостям (111). На процессы собственно спекания накладывается термическое травление, обусловленное присутствием в газовой атмосфере следов окислителя. Происходящее за счет него образование легко летучей моноокиси кремния и ее дальнейшие превращения приводят также к осаждению твердого $\mathrm{SiO}_{2}$ в разных формах. Процессы травления и осаждения $\mathrm{SiO}_{2}$ сильно зависят от распределения газового потока в трубе, и их влияние может быть сведено к минимуму с помощью экранировки поверхности образцов. Добавка к аргону 3\% водорода не оказывает заметного влияния на результаты отжига. Температурной зависимости и кинетике превращений, происходящих при отжиге в инертной среде, будет посвящена следующая работа.

Работа выполнена при финансовой поддержке РФФИ (грант № 15-08-02805), с использованием оборудования центра коллективного пользования „Материаловедение и диагностика в передовых технологиях“. 


\section{Список литературы}

[1] Izabela Kuzma-Filipek. Sintering of Porous Silicon. In: Handbook of Porous Silicon, ed. L. Canham (Springer International Publishing, Switzerland, 2014) p. 599.

[2] T. Yonehara, K. Sakaguchi, N. Sato. Appl. Phys. Lett., 64 (16), 2108 (1994).

[3] N. Sato, K. Sakaguchi, K. Yamagata, Y. Fujiyama, T. Yonehara. J. Electrochem. Soc., 142, 3116 (1995).

[4] R. Brendel, K. Feldrapp, R. Horbert, R. Auer. Phys. Status Solidi A, 197, 497 (2003).

[5] R. Brendel. Jpn. J. Appl. Phys., 40, pt. 1, 4431 (2001).

[6] G. Müller, M. Nerding, N. Ott, H.P. Strunk, R. Brendel. Phys. Status Solidi A, 197, 93 (2003).

[7] N. Ott, M. Nerding, G. Müller, R. Brendel, H.P. Strunk. J. Appl. Phys., 95, 497 (2004).

[8] I. Mizushima, T. Sato, S. Taniguchi, Y. Tsunashima. Appl. Phys. Lett., 77, 3290 (2000).

[9] T. Sato, I. Mizushima, S. Taniguchi, K. Takenaka, S. Shimonishi, H. Hayashi, M. Hatano, K. Sugihara, Y. Tsunashima. Jpn. J. Appl. Phys., 43, 12 (2004).

[10] D. Hernandez, T. Trifonov, M. Garın, R. Alcubilla. Appl. Phys. Lett. 102, 172102 (2013)

[11] M. Garin, D. Hernandez, T. Trifonov, D. Cardador, R. Alcubilla. 28th Eur. Photovoltaic Solar Energy Conf. and Exhibition (Paris, France, 2013) p. 933.

[12] M.E. Keeffe, C.C. Umbach, J.M. Blakely. J. Phys. Chem. Solids, 55, 965 (1994).

[13] H. Kuribayashi, R. Hiruta, R. Shimizu, K. Sudoh, H. Iwasaki. Jpn. J. Appl. Phys., 43 (4A), L 468 (2004).

[14] V. Depauw, O. Richard, H. Bender, I. Gordon, G. Beaucarne, J. Poortmans, R. Mertens, J.-P. Celis. Thin Sol. Films, 516, 6934 (2008).

[15] V. Depauw, I. Gordon, G. Beaucarne, J. Poortmans, R. Mertens, J.-P. Celis. J. Appl. Phys., 106, 033516 (2009).

[16] Y. Kumagai, K. Namba, T. Komeda, Y. Nishioka. J. Vac. Sci. Technol. A, 16, 1775 (1998).

[17] V. Lehmann. Electrochemistry of Silicon (Wiley-VCH, 2002).

[18] Н.Е. Преображенский, Е.В. Астрова, С.И. Павлов, В.Б. Воронков, А.М. Румянцев, В.В. Жданов. ФТП, 51, 79 (2017).

[19] T. Suzuki. J. Appl. Phys., 88, 6881 ( 2000).

[20] F.W. Smith, G. Ghidini. J. Electrochem. Soc.: Sol. St. Sci. Technol., 129, 1300 (1982).

[21] Н.А. Торопов, В.П. Барзаковский. Высокотемпературная химия силикатных и других окисных систем (М.-Л., Изд-во АН СССР, 1963).

[22] Я.Е. Гегузин, Ю.С. Кагановский. Диффузионные процессы на поверхности кристалла (М., Энергоатомиздат, 1984).

[23] D.J. Eaglesham, A.E. White, L.C. Feldman, N. Moriya, D.C. Jacobson. Phys. Rev. Lett., 70, 1643 (1993).

[24] K. Sudoh, H. Iwasaki, R. Hiruta, H. Kuribayashi, R. Shimizu. J. Appl. Phys., 105, 083536 (2009).

[25] Я.Е. Гегузин. Физика спекания 2-е изд. (М., Наука, 1984).

[26] T. Müller, D. Dantz, W.V. Ammon, J. Virbulis, U. Bethers. ECS Transactions, 2, 363 (2006).

[27] Б.И. Болтакс. Дифбузия и точечные дефбекты в полупроводниках (Л., Наука, 1972).

\section{High-temperature annealing of macroporous silicon in inert gas flow}

\author{
E.V. Astrova, N.E. Preobrazhenskiy, S.I. Pavlov, \\ V.B. Voronkov
}

loffe Institute, 194021 St. Petersburg, Russia

Abstract Interest in sintering of macroporous silicon is due to the ability of task-oriented modification of the structure. The annealing of macroporous structures in Ar atmosphere instead of $\mathrm{H}_{2}$ simplifies requirements to equipment and safety engineering. The current paper investigates sintering of macroporous silicon that takes place as result of annealing at $T=1000-1280^{\circ} \mathrm{C}$ in horizontal tube purged by high purity gases: $\mathrm{Ar}$ or $\mathrm{Ar}+3 \% \mathrm{H}_{2}$. Experiments are conducting on the layers with deep cylindrical macropores made by electrochemical etching of the samples with seed pits on the surface (ordered pores) and without seeds (random pores). Morphology of porous structure and changes in it after annealing were studied with electron and optical microscopes. It has been shown that depending on the pore diameter and treatment temperature the following transformation occurs. That is smoothing of the pore surface, pore closing and formation of surface crust, spheroidization and decomposition of cylindrical pores onto isolated hollow spheres, formation of a fine structure and faceting. It has been shown that (111) planes have the minimal surface energy. It was revealed that at annealing of macroporous silicon in inert gas atmosphere intensive thermal etching takes place. It leads to porosity increase or even full disappearance of the porous layer on the edge of a sample. Moreover, at annealing, especially in the low temperature range, oxide deposition is registered. The oxide is deposited as a film, balls or long filaments which form a glass wool. Observed features can be explained by the presence of the oxidizer traces in the inert gas, which causes formation of a highly volatile $\mathrm{SiO}$ and reactions with its participation.

Редактор Г.А. Оганесян 